\title{
Error Analysis of Model-based State-of-Charge Estimation for Lithium-Ion Batteries at Different Temperatures
}

\author{
Zhong Ren ${ }^{1,2}$, Changqing $\mathrm{Du}^{1,2}{ }^{*}$, Huawu Wang ${ }^{3}$ and Jianbo Shao ${ }^{1,2}$ \\ ${ }^{1}$ Hubei Key Laboratory of Advanced Technology for Automotive Components, Wuhan University of \\ Technology, Wuhan 430070, China; \\ ${ }^{2}$ Hubei Collaborative Innovation Center for Automotive Components Technology, Wuhan University of \\ Technology, Wuhan 430070, China; \\ ${ }^{3}$ Dongfeng Commercial Vehicle Co. Ltd., Wuhan 430070, China. \\ *E-mail: cq_du@whut.edu.cn
}

doi: $10.20964 / 2020.10 .03$

Received: 2 June 2020 / Accepted: 16 July 2020 / Published: 31 August 2020

\begin{abstract}
State-of-charge (SOC) estimation of lithium-ion batteries (LIBs) is one of the core functions of a battery management system (BMS). Until now, numerous approaches have been proposed to achieve highaccuracy SOC estimation, among which the model-based SOC estimation algorithm is the most popular algorithm implementation in an actual BMS. Since SOC estimation accuracy is directly influenced by battery model accuracy, it is essential to quantitatively analyze the relationship between model and SOC estimation accuracy, as well as the error sources of the model error. In this article, first, the model accuracy and SOC estimation accuracy are comprehensively studied based on the first-order resistancecapacitor (RC) model and extended Kalman filter (EKF) algorithm under the constant current discharge (CCD) test and Federal Urban Dynamic Schedule (FUDS) test at different test temperatures $\left(0^{\circ} \mathrm{C}, 10^{\circ} \mathrm{C}\right.$, $20^{\circ} \mathrm{C}, 30^{\circ} \mathrm{C}, 40^{\circ} \mathrm{C}$, and $50^{\circ} \mathrm{C}$ ). Second, regression and correlation analysis is applied to quantitatively evaluate the relationship between the normalized root-mean-square error (RMSE) of model and SOC estimation error. Third, the impact of the SOC open-circuit-voltage (OCV) curve, Ohmic resistance, impedance, and sensor error on SOC estimation accuracy are systematically studied as well. The results show that there is a one-dimensional linear positive relationship between model and SOC estimation accuracy, and the specific quantitative relationship is given. Among the parameters of the battery model, the accuracy of the SOC-OCV curve has the greatest influence on model and SOC estimation error compared to Ohmic resistance and impedance. In addition, compared to the effect of current sensor error, the voltage sensor error has a more significant impact on model and SOC estimation error.
\end{abstract}

Keywords: Lithium-Ion Battery; State-of-Charge Estimation; Extended Kalman Filter Algorithm; Error Analysis; Battery Management System 


\section{FULL TEXT}

(C) 2020 The Authors. Published by ESG (www.electrochemsci.org). This article is an open access article distributed under the terms and conditions of the Creative Commons Attribution license (http://creativecommons.org/licenses/by/4.0/). 